CYSTIC FIBROSIS

\title{
Inducible NO synthase expression is low in airway epithelium from young children with cystic fibrosis
}

\author{
A Moeller, F Horak Jr, C Lane, D Knight, A Kicic, S Brennan, P Franklin, J Terpolilli, \\ J H Wildhaber, S M Stick
}

See end of article for authors' affiliations

......................

Correspondence to:

Dr A Moeller, Department of Respiratory Medicine, University Children's Hospital Zurich,

Steinwiesstrasse $75, \mathrm{CH}$ -

8032 Zurich, Switzerland; alexander.moeller@kispi. unizh.ch

Received 19 October 2005 Accepted

19 February 2006

Published Online First

3 March 2006
Background: This is the first study to measure inducible nitric oxide synthase (iNOS) gene and protein expression quantitatively in primary epithelial cells from very young children with cystic fibrosis (CF). Low levels of exhaled nitric oxide (NO) in CF suggest dysregulation of NO production in the airway. Due to the importance of $\mathrm{NO}$ in cell homeostasis and innate immunity, any defect in the pathway associated with CF would be a potential target for treatment.

Methods: Cells were obtained by tracheobronchial brushing from 40 children with CF of mean (SD) age 2.1 (1.5) years and from 12 healthy non-atopic children aged 3.4 (1.2) years. Expression of iNOS mRNA was measured using quantitative PCR and iNOS protein by immunofluorescence and Western blot analysis.

Results: Inducible NOS mRNA expression was significantly lower in CF patients with and without bacterial infection than in healthy children $(0.22$ and $0.23 \vee 0.76 ; p=0.002$ and $p=0.01$, respectively). Low levels of iNOS gene expression were accompanied by low levels of iNOS protein expression as detected by Western blot analysis.

Conclusions: These results support the findings of previous studies in adult patients with advanced disease, cell lines, and animal models. Our findings reflect the situation in children with mild lung disease. They indicate that low iNOS expression may be an innate defect in CF with potential consequences for local antimicrobial defence and epithelial cell function and provide evidence for an approach to treatment based on increasing epithelial $\mathrm{NO}$ production or the sensitivity of NO dependent cellular processes.
C onsiderable efforts are currently being made to enable primary treatment of the genetic abnormality responsible for cystic fibrosis (CF) using a genetic based treatment for the disorder. In addition, strategies to ameliorate the effects of the genetic abnormality or of associated disease modifier genes may be helpful in the short to medium term. An example is the potential for abnormally low nitric oxide (NO) levels in the airways of patients with CF to affect critically normal epithelial function, thus contributing to the multifactorial pathogenesis of CF lung disease. Observations that include measurements of exhaled NO suggest an abnormality in the regulation of this important molecule in CF. The fractional concentration of exhaled $\mathrm{NO}\left(\mathrm{Fe}_{\mathrm{NO}}\right)$ is increased in a number of inflammatory disorders of the lung. ${ }^{1}$ However, despite the severity of airway inflammation, several studies have shown reduced orally or nasally exhaled NO levels in patients with $\mathrm{CF}^{2-6}$ Since there is evidence that inducible nitric oxide synthase (iNOS) in the airway epithelium is the major source of NO in exhaled breath, ${ }^{7}$ reduced epithelial iNOS activity is a plausible explanation for these observations. However, the data from studies that have examined epithelial iNOS activity are contradictory. ${ }^{89}$ Whether downregulation of epithelial iNOS in CF is a fundamental or even innate defect is important, given the crucial signalling, ${ }^{10}$ regulatory, ${ }^{10}$ and antibacterial activities of NO. ${ }^{11}{ }^{12}$ The effects of low iNOS expression on cell homeostasis and the failure of epithelial cells to respond to pathogens by producing NO could represent the loss of a crucial first line epithelial defence mechanism. If so, correcting the $\operatorname{defect}(\mathrm{s})$ might represent a useful therapeutic strategy that could be implemented from birth.
Previous studies of epithelial iNOS activity in CF have generally used semi-quantitative techniques, ${ }^{13}$ examined immortalised cell lines ${ }^{9}{ }^{14}$ or, in studies of primary epithelial cells, iNOS activity has mostly been determined in samples from subjects with significant lung disease or older subjects than those included in the present study. ${ }^{8}{ }^{9}$ Overall, studies to date have not helped to determine whether low iNOS expression is a primary effect or at least present from an early age in CF. In this report we present definitive evidence that iNOS is reduced in airway epithelial cells from young children with CF compared with control children with no evidence of respiratory disease or atopy.

We therefore studied very young children with CF with mild lung disease to determine epithelial iNOS gene and protein expression in early life. Given that newborn screening allows for early intervention to prevent lung disease in CF, the question of whether there is primary dysfunction of iNOS is important to answer if the NO pathway is to be further investigated as a therapeutic target. We present evidence to support the hypothesis that decreased iNOS expression in CF epithelium is a primary phenomenon and thus indicate a clear rationale for investigating the potential therapeutic benefits of manipulating the epithelial NO pathway in CF.

\section{METHODS}

\section{Subjects}

Forty young children with CF (20 boys, 20 girls) of mean (SD) age 2.1 ( 1.5 ) years (range $0.12-5.6$ ) and 12 healthy nonatopic controls free of previous or current respiratory disease

Abbreviations: BAL, bronchoalveolar lavage; CF, cystic fibrosis; cfu, colony forming units; iNOS, inducible NO synthase; NO, nitric oxide 
Table 1 Characteristics of children with cystic fibrosis and healthy controls

\begin{tabular}{|c|c|c|c|}
\hline & CFA $(n=16)$ & CFB $(n=24)$ & Healthy $(n=12)$ \\
\hline Age (years) ${ }^{*}$ & $1.15(0.83)$ & $2.7(1.5)$ & $3.3(1.2)$ \\
\hline$M / F$ & $9 / 7$ & $11 / 13$ & \\
\hline Symptom scoreł & $13.5(2.2)$ & $14.6(2.7)$ & \\
\hline Cells from TB $\left(\times 10^{6}\right)^{*}$ & $1.84(0.67)$ & $1.9(1.07)$ & $1.52(0.7)$ \\
\hline \multicolumn{4}{|l|}{ Genotype } \\
\hline dF508 homozygote & $50 \%$ & $66.7 \%$ & NA \\
\hline dF508 heteroygote & $43.75 \%$ & $29.2 \%$ & \\
\hline G542X/G542X & - & $4.2 \%$ & \\
\hline \multirow{2}{*}{\multicolumn{4}{|c|}{ Cells in BAL fluid }} \\
\hline & & & \\
\hline $\mathrm{TCC}\left(\right.$ cells $\left.\times 10^{3} / \mathrm{ml}\right) \dagger$ & 345.3 (236 to 506 ) & 443.5 (285 to 690$)$ & NA \\
\hline Neutrophils (cells $\times 10^{3} / \mathrm{ml}$ ) $†$ & 55.9 (29.5 to 105.9$)$ & 88.4 (43.2 to 181.1$)$ & \\
\hline Neutrophils (\%)* & $22.6(18.9)$ & $28.3(23.2)$ & \\
\hline iNOS expression $\dagger$ & $0.23(0.11$ to 0.46$)$ & $0.22(0.14$ to 0.34$)$ & $0.76(0.51$ to 1.14$)$ \\
\hline \multicolumn{4}{|c|}{$\begin{array}{l}\text { SD, standard deviation; BAL, bronchoalveolar lavage; TB, tracheobronchial brushing; TCC, total cell count per m } \\
\text { BAL fluid; CFA, CF without bacterial infection at actual or previous BAL; CFB, CF with bacterial infection either in } \\
\text { present or previous BAL. } \\
\text { "Mean (SD). } \\
\text { †Geometric mean (95\% confidence interval). } \\
\text { fCystic fibrosis clinical score. } \\
\text { ( Heterozygote mutations included: unknown mutation ( } \mathrm{n}=5), \mathrm{N} 310, \mathrm{G} 551 \mathrm{D}, \mathrm{R} 117(\mathrm{H}, \mathrm{R} 553 \mathrm{X}, \mathrm{P} 67 \mathrm{~L}, \mathrm{~S} 1235 \mathrm{R} \text {, } \\
\text { W1282 ( } \mathrm{n}=1 \text { ). } \\
\text { §This patient was compound heterozygote with one unidentified allele and a positive sweat test. }\end{array}$} \\
\hline
\end{tabular}

of mean (SD) age 3.3 (1.2) years (range 1.1-5.1) were included in the study (table 1). Current symptoms of CF patients were scored using the cystic fibrosis clinical score (CFCS). ${ }^{15}$

\section{Study design}

This study was carried out at a single center (Princess Margaret Hospital for Children (PMH), Perth, Western Australia). Since 1997 all children under 6 years of age are given the opportunity to take part in the clinical bronchoalveolar lavage (BAL) programme to identify respiratory pathogens. BAL is performed in newly diagnosed children with CF and repeated annually as part of the clinical assessment until the children are able to expectorate sputum. The diagnosis of CF was confirmed by a sweat chloride level of $\geqslant 60 \mathrm{mmol} / \mathrm{l}$ and gene mutation analysis, screening initially for four common mutations and up to 270 mutations for unknown compound heterozygotes identified. Parents are asked for permission to perform tracheobronchial brushing prior to the BAL.

The healthy children were studied as part of a programme to investigate epithelial function in asthma ${ }^{7}$ and were intubated and anaesthetised for a non-respiratory elective surgical procedure. This included upper or lower gastrointestinal endoscopy. Five of the healthy controls had celiac disease and endoscopy was performed to investigate the effect of their diet. In four of them gastrointestinal endoscopy revealed normal findings, whereas in one patient some changes were found. In one child with a family history of celiac disease, this was ruled out by normal findings. One child was assessed for gastro-oesophageal reflux and showed normal findings. Five children were assessed for failure to thrive, iron deficiency or constipation, respectively. Atopic sensitisation was excluded by skin prick testing to eight locally prevalent allergens and the absence of current or previous respiratory symptoms confirmed using a validated questionnaire. ${ }^{16}$

Transbronchial brushing was conducted under general anaesthesia using sevofluorane for induction and intravenous propofol for maintenance in all children. For the patients with $\mathrm{CF}$, bacteriology, virology and inflammatory cell analyses were conducted on BAL supernatant. Inducible NOS gene and protein expression was determined in airway epithelial cells collected by transbronchial brushing.
The study was approved by the Princess Margaret Hospital for Children ethics committee and informed written consent was obtained for all subjects.

\section{Techniques}

Tracheobronchial brushing

Epithelial cells were obtained from the distal trachea during anaesthesia using a cytology brush (BC 25105, Olympus, Australia) as previously described. ${ }^{7}$ This brushing procedure was repeated 3-5 times. The brush was then withdrawn and agitated in $5 \mathrm{ml}$ bronchial epithelial basal media (Clonetics, CA, USA) to remove epithelial cells. Cell samples were placed on ice and immediately taken to the laboratory and processed within 15 minutes of sampling. An aliquot $(20 \mu \mathrm{l})$ of the resulting cell suspension was diluted 1:2 with trypan blue to determine cell number and viability using a Neubauer haemocytometer. The cells sampled consisted of 95-98\% epithelial cells with 2-5\% macrophages. Immunocytochemical staining of the cytospins was used to confirm the purity of the epithelial sample as described previously. ${ }^{17}$

\section{Expression of iNOS}

Macrophages were removed by positive selection using CD-68 antibody as previously described, ${ }^{7}$ and cytospin slides were then fixed, washed, and blocked in $5 \%$ bovine serum albumin (BSA) $(\mathrm{w} / \mathrm{v}), 10 \%$ fetal calve serum (FCS) $(\mathrm{v} / \mathrm{v})$, and $0.1 \%$ Triton X-100 in $1 \times$ Tris buffered saline (TBS) for 1 hour at room temperature. Cells were then incubated with the primary antibody (iNOS; 1:100; Santa Cruz, CA, USA) for 24 hours at $4^{\circ} \mathrm{C}$ followed by the secondary fluorescently conjugated antibody (rabbit anti-goat IgG FITC conjugated; Sigma, MO, USA) for a similar period, after which the antibody complex was visualised using a fluorescent microscope (Leica Microsystems, Australia). In addition to immunohistochemistry, protein levels were also measured using Western blot analysis. Briefly, epithelial cells $\left(2.5 \times 10^{7}\right)$ were harvested by centrifugation at $1000 \mathrm{~g}$ for 5 minutes, washed once with ice cold phosphate buffered saline and resuspended in $600 \mu \mathrm{l}$ ice cold lysis buffer $(20 \mathrm{mM}$ Tris, $1 \mathrm{mM}$ ETDA ( $\mathrm{pH} 7.4$ ), 1 mM DTT (dithiothreitol) and $50 \mu \mathrm{l}$ of a protease cocktail mixture containing $10^{4} \mathrm{mM}$ 4-(2aminoethyl)benzenesulfonyl fluoride (AESF), $0.08 \mathrm{mM}$ aprotinin, $2 \mathrm{mM}$ leupeptin, $4 \mathrm{mM}$ bestatin, $1.5 \mathrm{mM}$ pepstatin $\mathrm{A}$ 
and $1.4 \mathrm{mM} \mathrm{E-64).} \mathrm{On} \mathrm{ice,} \mathrm{the} \mathrm{cells} \mathrm{were} \mathrm{disrupted} \mathrm{by}$ passage through a 27 gauge needle. Protein concentrations were determined using the Bicinchoninic Acid (BCA) protein assay (Pierce, IL, USA). A total of $40 \mu \mathrm{g}$ of protein was electrophoresed on $8 \%$ SDS-PAGE gels, transferred to PVDF membranes, and immunoblotted using a polyclonal iNOS antibody (1:200, Santa Cruz, CA, USA). iNOS was visualised using the enhanced chemoluminescence (ECL-Plus) Western blotting detection system (Amersham Biosciences, IL, USA). The protein content was estimated from Western blots by densitometry using Quantity One software (BIORAD, NSW, Australia).

iNOS expression was quantified using a method previously published. ${ }^{7}$ In brief, RNA was extracted from epithelial cells using the Qiagen RNeasy mini kit (Qiagen, Victoria, Australia). Total RNA was eluted in $50 \mathrm{ml}$ RNase-free water and cDNA synthesised by reverse transcription using TaqMan Reverse Transcription Reagents (Applied Biosystems, CA, USA). Expression of NOS2 gene was quantified relative to the expression of the "housekeeping gene" $\beta$-actin ${ }^{18}$ using Taqman real time polymerase chain reaction (PCR). The $\beta$ actin primers and probes used for this study were obtained from Applied Biosystems (CA, USA) and, as such, the sequence data are proprietary. PCR was performed using the ABI Prism 7700 Sequence Detection System (PerkinElmer, CA, USA). cDNA was incubated in a $25 \mathrm{ml}$ reaction volume containing 16Taqman Universal PCR Master Mix (Applied Biosystems, NSW, Australia), forward primer (10 mM), reverse primer $(10 \mathrm{mM})$, and probe $(200 \mathrm{nM})$. Signals were analysed by the ABI Prism Sequence Detection System software version 1.9.

\section{Bronchoalveolar lavage}

In patients with $\mathrm{CF}$, bronchoalveolar lavage was carried out according to a standardised technique. ${ }^{19}$ Briefly, three aliquots of normal saline ( $1 \mathrm{ml} / \mathrm{kg}$ body weight) were instilled into the right middle lobe or right lower lobe and retrieved using low pressure suction. The first aliquot was sent to the Department of Microbiology for identification of bacteria, fungal elements, and viruses. The remaining aliquots were pooled and stored on ice until processed (within 2 hours). Total cell count (TCC; cells $\times 10^{3} / \mathrm{ml}$ BAL fluid retrieved), absolute neutrophil numbers (PMN; cells $\times 10^{3} / \mathrm{ml}$ ), and percentage neutrophils of TCC (\%PMN) were calculated.

\section{Microbiology}

BAL samples from patients with CF were cultured on blood, CLED, Fildes and Sabouraud agar with chloramphenicol. Viruses (RSV, parainfluenza, influenza A/B, adenovirus, CMV) were detected using direct immunoflourescence and/ or rapid viral tissue culture. Significant microbial infection was considered as $>10^{4}$ colony forming units $(\mathrm{cfu}) / \mathrm{ml}$. Bacterial density between $10^{2}$ and $10^{4} \mathrm{cfu} / \mathrm{ml}$ were recorded as isolated colonies. The presence of mixed oral flora was not considered pathogenic but was recorded.

\section{Statistical analysis}

Anthropometric data and \% PMN in BAL fluid were normally distributed and expressed as mean (SD). The data for iNOS, TCC, and PMN were log normally distributed and are presented as geometric mean (GM) with 95\% confidence intervals $(95 \% \mathrm{CI})$. Statistical analyses were performed using the $\log$ (basel0) for these variables allowing parametric tests to be performed. A Student's $t$ test or one-way analysis of variance (ANOVA) was used to test for significant differences between groups. Pearson moment correlation was used to test for associations between NOS expression and inflammatory cell data. All analyses were performed using SigmaStat for Windows 2.03 (SPSS Inc).

\section{RESULTS}

The 40 children with CF were divided into two groups based on a history of bacterial colonisation. Infection was defined as $\geqslant 10^{4}$ cfu for any of the common pathogens. The two groups were (1) CF without bacterial infection (CFA), consisting of children who had never had significant infection $(\mathrm{n}=16)$, and (2) CF with infection (CFB) which comprised children with bacterial infection either in the most recent or a previous $\mathrm{BAL},(\mathrm{n}=24$; table 1$)$. The CFA group was significantly younger than the CFB group (mean (SD) $1.15(0.83) v 2.7(1.5)$ years, $\mathrm{p}=0.001)$. The healthy children were significantly older than the CFA group (3.3 (1.2) $v 1.15$ $(0.83)$ years; $\mathrm{p}<0.001)$ but were of similar age to the CFB group (3.3 (1.2) v $2.7(1.5)$ years; $\mathrm{p}=0.25)$.

The CFB group comprised 14 children with significant bacterial growths in a previous but not in the most recent BAL and 10 children with bacterial infection in the most recent BAL $\left(>10^{4} \mathrm{cfu} / \mathrm{ml}\right)$. Nine of the 10 children with recently documented infection had repeatedly positive cultures in their successive BALs, whereas one child showed the first significant colonisation. There was no difference in age between these two CFB subgroups $(p=0.2)$. Most of the children with infection in the most recent BAL showed cocultures of two or more pathogens. Pseudomonas aeruginosa was isolated in six of these children. Other pathogens were Haemophilus influenzae $(\mathrm{n}=6)$, Stenotrophomonas maltophilia $(\mathrm{n}=3)$, Staphylococcus aureus $(\mathrm{n}=2), E$ coli $(\mathrm{n}=2)$ and Enterobacter $(\mathrm{n}=1)$. One child showed a positive culture of cytomegalovirus in addition to $P$ aeruginosa and Enterobacter.

The mean (SD) number of epithelial cells obtained per sample by brushing was $1.86(0.93)$ million in the CF group and was similar to the $1.52(0.7)$ million cells obtained in the control group $(p=0.2)$. The mean viability of the cells sampled was $17.3 \%$ and did not differ between CF and healthy groups.

Initially, endogenous iNOS protein expression was determined in healthy children and young CF patients. Immunohistochemical results indicated that iNOS staining intensity was greater in healthy non-atopic children than in CF children. However, the pattern of staining was similar in both phenotypes with the majority of staining occurring at the apical surface of the cells (fig 1A). Differential iNOS protein expression was further confirmed using Western blot analysis. A higher level of iNOS protein expression was observed in healthy non-atopic children than in children with CF (fig 1B), correlating with the immunohistochemical results obtained initially. Equal loading of samples was confirmed by the expression of $\beta$-actin. When the protein was quantified, healthy non-atopic children were found to express a significantly greater amount $(>2.5$ fold; $\mathrm{p}=0.0078$ ) of iNOS than their CF counterparts (fig 1C).

Inducible NOS mRNA was detectable in all samples from patients with CF and healthy controls (fig 2). Geometric mean (95\% CI) iNOS expression (mRNA) was 0.23 (0.11 to $0.46)$ in the CFA group and $0.22(0.14$ to 0.34$)$ in the CFB group. There was no significant difference between the two groups of patients with CF $(p=0.7)$. Children with positive bacterial cultures in the most recent BAL (CFB group) had a slightly lower geometric mean iNOS expression $(0.13$ (95\% CI 0.07 to 0.24 ) than children who had significant bacterial growth in a previous BAL but not in the most recent BAL $(0.24(95 \%$ CI 0.14 to 0.41$)$ and those in the CFA group $(0.23$ ( $95 \%$ CI 0.11 to 0.46 ), but the difference was not statistically significant (one way ANOVA, $\mathrm{p}=0.3$; individual $t$ tests, $\mathrm{p}=0.26$ and 0.12 , respectively). There were no differences in iNOS expression between children with or without $P$ 
A
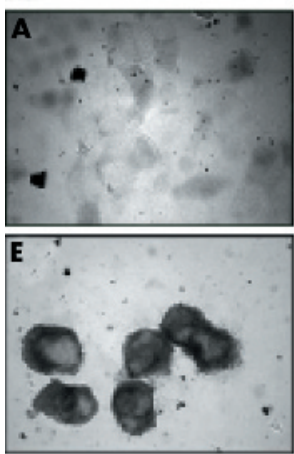

B

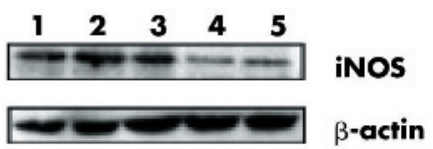

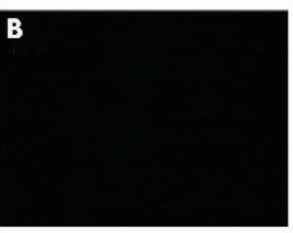
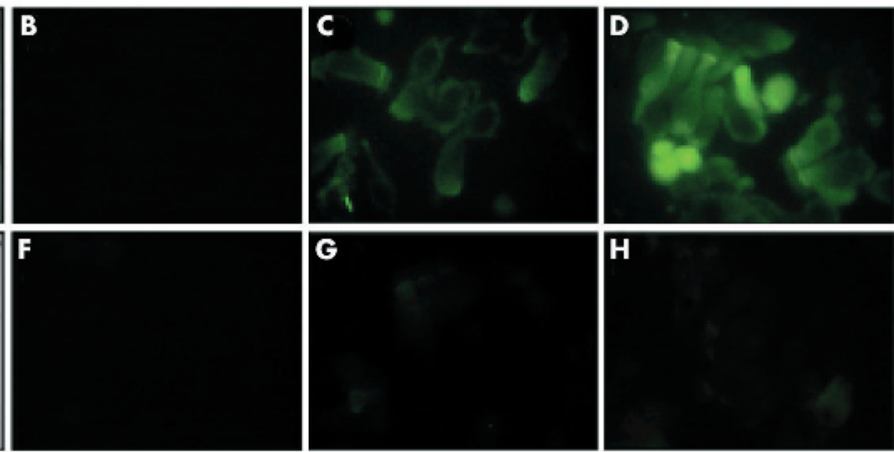

C iNOS protein expression

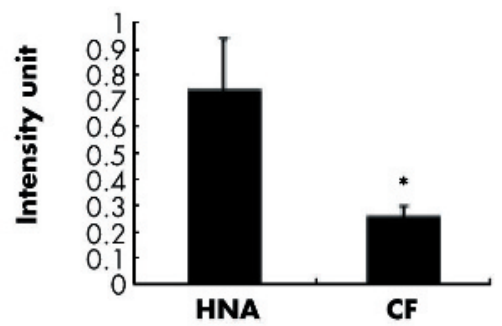

Figure 1 (A) A and E are phase contrast micrographs of epithelial cell cytospins derived from healthy non-atopic and CF patients; B and F are negative controls for iNOS; C and D are two representative samples of endogenous iNOS expression in epithelial cells from healthy non-atopic children $(n=15) ; G$ and $H$ are two representative samples of endogenous iNOS expression in epithelial cells from CF patients $(n=15)$; magnification $1000 \times$. (B) Western blot analysis of endogenous iNOS expression between phenotypes: lane 1, lipopolysaccharide stimulated 16HBEs; lane 2, healthy non-atopic representative patient 1 ; lane 3, healthy non-atopic representative patient 2; lane 4, CF representative patient 1; lane 5, CF representative patient 2. (C) Protein expression from the two CF patients shown in (B). Quantification of protein expression showed a significant difference $(p=0.0078)$ in iNOS expression between healthy non-atopic children and those with CF. Values are mean (SD).

aeruginosa isolates in the most recent BAL. Inducible NOS expression in cells from healthy children was 0.76 (95\% CI 0.51 to 1.14 ) and was significantly higher than both the CFA $(\mathrm{p}=0.01)$ and CFB $(\mathrm{p}=0.002)$ groups. Levels of iNOS expression were independent of sex and weight in all groups, but there was a statistically significant positive correlation for iNOS with age in children with CF $\left(r^{2}=0.104 ; \mathrm{p}=0.04\right)$. The correlation with age was confined to the $\mathrm{CFB}$ group $\left(r^{2}=0.36 ; \mathrm{p}=0.002\right)$.

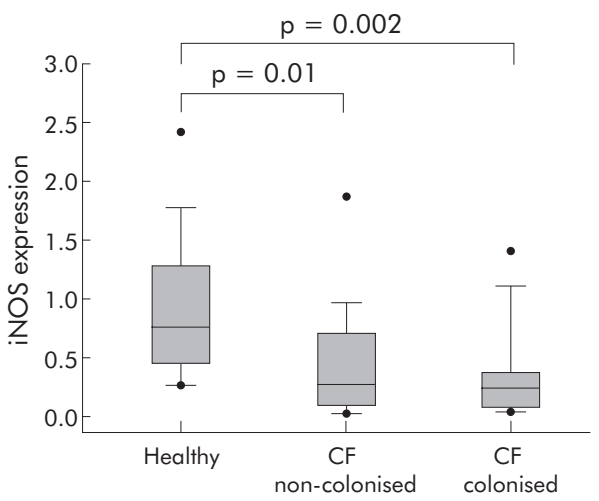

Figure 2 Expression of iNOS on epithelial cells from children with cystic fibrosis, including children with recent or past bacterial infection $\left(\geqslant 10^{4}\right.$ colony forming units/ml BAL fluid; $\left.n=24\right)$, children with no infection $(n=16)$, and healthy children $(n=12)$ quantified relative to the expression of $\beta$-actin as the housekeeping gene using TaqMan real time PCR. ${ }^{19}$ The lines bisecting the boxes are medians, the box limits represent 25 th and 75 th percentiles, whiskers extend to the 10th and 90 th percentiles, and the black dots represent outliers.
Twenty four children with CF (eight CFA) were homozygotes for dF508/dF508, 14 (seven CFA) were heterozygotes (dF508/-), one child with infection G542X/G542X and one compound heterozygote with one unidentified allele and a positive sweat test (without infection). There were no differences in iNOS expression (mRNA) between the dF508 homozygote and compound heterozygote children $(\mathrm{p}=0.12)$. The geometric mean TCC in BAL fluid samples of patients with CF was $401.2 \times 10^{3}$ (95\% CI 295.7 to 544.4 ) which was similar to that reported in healthy children. ${ }^{20}$ The absolute PMN number was $74.1 \times 10^{3}(95 \%$ CI 44.8 to 122.4 ) and mean (SD) \%PMN was 26.1 (21.5), both higher than that reported for healthy children but lower than that reported for similarly aged children with CF. ${ }^{20}$ No differences were observed in TCC, PMN number, and \%PMN between CFA and CFB groups ( $p=0.44,0.4$ and 0.42 , respectively). However, CF patients with significant pathogens in the most recent BAL had a geometric mean TCC of $554.9 \times 10^{3}$ (95\% CI 266.6 to 1154.9 ) compared with 352.1 (95\% CI 241.0 to 514.6 ) in the CFA group and 369.4 (95\% CI 273.9 to 498.1 ) in those with previous infection but sterile current BAL. Although there was a higher geometric mean, the difference was not significant $(\mathrm{p}=0.8$ and 0.3 , respectively). However, \%PMN were significantly higher in children with actual infection (mean (SD) 40.3 (27.8)) than in the CFA group (20.75 (17.5); $\mathrm{p}=0.037)$ and in patients with positive BAL cultures only in the past $(21.9(17.1) ; \mathrm{p}=0.05)$. No significant differences were found in TCC or \%PMN between children with and without growth of $P$ aeruginosa in the most recent BAL. There were no significant associations between any of the BAL cell count variables and iNOS expression (mRNA) in either the whole CF group or in either of the two CF subgroups separately. 
Table 2 Studies with quantitative or semi-quantitative assessment of iNOS expression in cystic fibrosis

\begin{tabular}{|c|c|c|c|c|c|c|}
\hline Study & Cell source & $\begin{array}{l}\text { CF:controls } \\
\text { (n) }\end{array}$ & $\begin{array}{l}\text { Age (years) } \\
\text { CF:controls }\end{array}$ & Nature of controls & Outcomes & iNOS expression \\
\hline Wooldridge $^{13}$ & Ex vivo bronchoscopy & $17: 14^{*}$ & $6.5: 3.5$ & $\begin{array}{l}\text { Respiratory disease } \\
\text { or symptoms }\end{array}$ & Semi-quantitative $\mathrm{IHC}$ & No difference \\
\hline Darling $^{21}$ & CFBE41 & - & - & $16 \mathrm{HBE}$ & Chemiluminescence & Low NO production \\
\hline Meng $^{14}$ & CFBE41 & - & - & $16 \mathrm{HBE}$ & PCR, Western & Reduced \\
\hline Meng & CFBE41 biopsy & $13: 14$ & $>19$ & $16 \mathrm{HBE}+$ emphysema & PCR, Western & Reduced \\
\hline Kelley ${ }^{8}$ & Murine transgenic line & & & Non-CF mice & PCR, Western & Reduced \\
\hline Morrissey ${ }^{22}$ & Ex vivo lung sections & $5: 3$ & $21-42: 50-68$ & Lung cancer & Semi-quantitative $\mathrm{IHC}$ & Reduced \\
\hline Dotsch $^{6}$ & Ex vivo nasal polyps & $3: 4$ & $13-18: 40-59$ & Non-CF nasal polyps & PCR & Reduced \\
\hline Steagall ${ }^{23}$ & Murine CFTR knock out & - & - & CFTR+/+ mice & IHC, PCR, Iso NO-meter & Reduced to absent \\
\hline $\mathrm{Kahn}^{24}$ & Ex vivo lung sections & 7:9† & - & $\begin{array}{l}\text { Healthy + non-CF } \\
\text { lung disease }\end{array}$ & $\begin{array}{l}\text { PCR, Western IFN- } \gamma \\
\text { stimulation }\end{array}$ & $\begin{array}{l}\text { Reduced iNOS } \\
\text { promoter activity }\end{array}$ \\
\hline
\end{tabular}

CFBE41, CF airway epithelial cell line 41; 16HBE, human bronchial epithelial cell line; IHC, immunohistochemistry; PCR, polymerase chain reaction; Western: western-blot; $\mathrm{NO}$ : nitric oxide.

${ }^{*} 11 / 17 \mathrm{CF}$ and $9 / 14$ non-CF samples allowed ICH analysis of NOS expression.

†Five samples from explanted non-CF lungs and four samples by bronchoscopic brushing of healthy volunteers.

\section{DISCUSSION}

This is the first study to measure iNOS quantitatively in primary epithelial cells from very young children with CF. Previous studies have used semi-quantitative methods such as immunohistochemistry. ${ }^{13}$ Quantitative studies using real time PCR have previously been carried out either in immortalised cell lines or in epithelial cells from adult patients with CF and, although suggesting low expression of NOS, they could not rule out low expression resulting from processes associated with advanced lung disease. ${ }^{89}{ }^{14}$ We hypothesised that iNOS gene and protein expression would be low in epithelium from young children with CF with mild lung disease due to a primary low iNOS gene expression in CF epithelium. Until now this hypothesis has been difficult to test because of problems obtaining samples of epithelial cells from very young children with $\mathrm{CF}$ and having samples from truly healthy controls for comparison. Our newborn CF surveillance programme has provided an opportunity to obtain samples from children with CF soon after birth, and an ongoing programme to study epithelial function during childhood has enabled us to obtain samples from healthy young children. ${ }^{7}$

We have shown that the expression of iNOS in airway epithelial cells from children with CF is lower than expression in cells from healthy children. Past or present airway colonisation with bacterial pathogens did not influence the expression of iNOS in the epithelial cells.

Our observations contrast with those of the only other study to investigate iNOS expression in epithelium from children with CF. Wooldridge et al ${ }^{13}$ reported similar iNOS expression in $\mathrm{CF}$ and non-CF epithelium. However, there are important differences between our study and that of Wooldridge. We used a fully quantitative technique to measure iNOS mRNA expression in contrast to the semiquantitative immunostaining technique used by Wooldridge and colleagues. Furthermore, the latter report included only eight children in the age range that we studied. Finally, our control subjects were free of respiratory disease or symptoms whereas the controls reported by Wooldridge included subjects with a variety of respiratory conditions. Our observations regarding iNOS gene expression were supported by quantitative and semi-quantitative assessments of protein expression. To date, studies have not been able to determine whether the low iNOS expression is present from an early age in children with CF-that is, whether this is a primary defect (table 2).

Since epithelial iNOS expression is an important determinant of NO in exhaled breath, ${ }^{7}$ the low NO levels in exhaled air of patients with $\mathrm{CF}^{2-6}$ are likely to be explained by low iNOS expression in the epithelium. Other factors such as the apparent trapping and metabolism of NO within the mucus and by colonising bacteria suggested by others ${ }^{25-27}$ are also likely to contribute to low NO in exhaled breath, but are possibly less significant factors early in the course of CF airway disease and before colonisation.

Studies using CFBE410 epithelial cell lines have shown that iNOS expression does not increase in response to cytokine stimulation ${ }^{9}$ or neutrophil co-culture. ${ }^{14}$ These studies suggest a defect at some point in the chain of events leading to transcription, but there are only limited data using primary cells. Zheng and colleagues ${ }^{28}$ described a defect in autocrine activation of NOS2 in primary cells from CF patients when stimulated; however, whether this is a primary phenomenon has not been clarified since samples were not obtained from young children.

Lung disease is the predominant cause of morbidity and mortality in CF and airway inflammation and bacterial colonisation can be detected early in childhood. ${ }^{29-31}$ The chronic colonisation by pathogens such as $P$ aeruginosa is one of the most important factors in the rate of progression of lung disease in children with $\mathrm{CF}^{32}{ }^{33}$ However, bacterial infection did not affect levels of iNOS expression in our study. These results agree with previous observations in CF mice ${ }^{8}$ and in humans ${ }^{13}$ However, in the colonised group there was a weak but significant positive correlation between age and iNOS expression. The reason for the observed increase in iNOS expression with age is not clear. This observation does not seem to be due to developmental changes in iNOS expression because there was no such relationship in the healthy children. Furthermore, the increase in iNOS expression with age in the colonised group of patients with CF did not appear to be a consequence of airway inflammation because there was no association between iNOS and any marker of inflammation in the BAL fluid that we examined. Although significant, the correlation is very weak. Therefore, since the relationship between age and iNOS expression was not a primary outcome for this study, it is feasible that the observation is a statistical artifact due to small numbers. The observation does not invalidate our argument that iNOS expression is lower in CF epithelium than in epithelium from the healthy group and, indeed, this result would tend to reduce the difference in iNOS expression between the healthy and CF groups.

Overall symptoms in the CF patients were assessed using the $\mathrm{CFCS}^{15}$ with a range from a minimum of 10 to a maximum of 50 points. The mean score of the subgroup of non-colonised children (CFA) in our study was 13.5, which is in the very low range. These mild clinical symptoms were in agreement with missing airway colonisation and only slightly increased neutrophil numbers in BAL fluid. This subgroup is 
therefore considered to have mild lung disease. On the basis of this, we believe that we can fairly argue that the observations regarding NOS expression in this study are unlikely to be secondary to lung disease and are likely to represent primary levels of expression. This assertion is supported by our observation that NOS expression was unrelated to PMN numbers in BAL fluid aspirate. The lack of correlation between infection and inflammation based on BAL fluid analysis and iNOS expression may be due to some extent to the different locus of sampling. TBB was performed in the central airways, whereas BAL may provide information on more distal airways. Some relation between local peripheral iNOS expression and local airway inflammation cannot therefore be excluded. In a given patient, the level of inflammation and infection may also vary between different lung regions, which may be an additional factor. To test whether there was a relationship between local iNOS expression and local inflammation, airway biopsies would be needed and this is not ethically justifiable in this population.

Our samples were obtained from central airways and therefore might not represent peripheral airway iNOS expression. However, our results are in agreement with studies investigating explanted airways and lung tissue. ${ }^{89}$ Whereas Kelley et al ${ }^{8}$ showed nearly absent immunostaining for iNOS in CF tracheal sections, Meng et al ${ }^{9}$ found reduced staining for iNOS and less iNOS RNA in CF epithelium deriving from explanted lungs, hence peripheral airways.

Low iNOS expression resulting in low levels of NO in the airway could have an important impact on the airway defence against bacterial colonisation. Grasemann and colleagues have shown that low $\mathrm{Fe}_{\mathrm{NO}}$ was associated with an increased rate of bacterial colonisation of the CF airways ${ }^{34}$ and, while it is possible that this is a secondary phenomenon, there are abundant studies that indicate an important role for NO in primary host defences in the lung. In animal models and in humans, NO production is increased in response to infection. ${ }^{10} 142135$ NO enhances bacterial clearance from lung tissue $^{8}$ and inhibition of iNOS increases susceptibility to infection. $^{2136}$ Also, in animal models, Pseudomonas lung infection is associated with reduced iNOS expression ${ }^{37}$ and activity. ${ }^{36}$ The low iNOS expression observed in our young children with CF could thus increase their susceptibility to chronic bacterial colonisation and infection and suggests a role for treatments aimed at increasing NO production by airway epithelial cells.

It has recently been suggested that iNOS expression can be downregulated in astrocytes by decreased availability of Larginine or overexpression of arginase. ${ }^{38}$ A similar mechanism could contribute to low iNOS expression in CF airways as high arginase activity has recently been found in the sputum of patients with CF. The high arginase activity has been interpreted as a direct result of neutrophilic inflammation, hence as a secondary effect to airway inflammation. ${ }^{39}$ Furthermore, arginases are not only expressed in human cells but also by bacteria such as Staph aureus and $P$ aeruginosa. However, this is less likely to be responsible for our observations since the airway neutrophil count was only mildly increased. Clearly, this is an issue that requires further investigation.

While increasing airway NO concentrations might improve local antibacterial host defences in CF, a recent study provides a rationale for manipulation of the airway epithelial NO pathway. Dormer and colleagues ${ }^{40}$ observed primary nasal epithelial cells from patients with CF and reported relocation of cytoplasmic CFTR to the apical cell surface and improvement in chloride channel function following treatment with a $5^{\prime}$ phosphodiesterase inhibitor (sildenafil). NO has been shown to upregulate the production of guanosine $3^{\prime}, 5^{\prime}$-cyclic monophosphate (cGMP) via the activation of soluble guanylate cyclase activity. ${ }^{41}$ Further, endogenous NO production plays some role in the downregulation of sodium absorption and leads to an increase in CFTR related and CFTR independent transepithelial chloride secretion. ${ }^{41}{ }^{42}$ Low NO production may therefore contribute to CF related dysfunction in epithelial ion transport by altering the cGMP production. The inhibition of phosphodiesterase enzymes by the CGMP specific 5' phosphodiesterase inhibitor thus results in an increase in CGMP and may therefore increase the sensitivity to NO. More important is the potential to directly improve cGMP dependent processes such as endogenous CFTR activation and stimulation of CFTR independent, hence alternative, chloride conductance. ${ }^{41-43}$

In this study we have quantitatively measured, for the first time, iNOS expression in primary epithelial cells in children under the age of 5 years with CF. Inducible NOS gene and protein expression was significantly reduced in CF epithelial cells compared with cells derived from healthy controls. Our findings reflect the situation in young children with CF without advanced disease and therefore indicate that low iNOS expression may be a primary defect. We believe these data differentiate our observations from previously published data and suggest a new therapeutic approach commencing immediately following diagnosis in the newborn period with the aims of raising local NO levels or sensitivity of NO dependent pathways in the airway epithelium. There are limited data clinical data in support of this approach, ${ }^{38}{ }^{39}$ but our data provide evidence that a functionally important defect in the iNOS pathway in CF, present from early age, is a worthwhile target for treatment.

\section{ACKNOWLEDGEMENTS}

The authors thank Graham Hall for the statistical advice and Scott Burgess and Richelle Searles for the help in the sample collection and preparation. Dr Ross Graham and Ms Anita Chua are sincerely thanked for assisting in the protein quantification.

\section{Authors' affiliations}

A Moeller, F HorakJr, C Lane, A Kicic, J Terpolilli, S M Stick, Department of Respiratory Medicine, Princess Margaret Hospital for Children, Perth, Western Australia

A Moeller, J H Wildhaber, Division of Respiratory Medicine, University Children's Hospital, Zurich, Switzerland

A Kicic, P Franklin, School of Paediatrics and Child Health, University of Western Australia, Nedlands, Western Australia

F Horak Jr, Department of General Pediatrics, University Children's Hospital, Vienna, Austria

S Brennan, Telethon Institute for Child Health Research, Centre for Child Health Research, University of Western Australia, Western Australia

D Knight, James Hogg iCAPTURE Centre for Cardiovascular and Respiratory Research, St Paul's Hospital, Vancouver, BC, Canada

A Moeller was supported by a grant from the Swiss National Research Foundation. F Horak was supported by a grant of the Austrian Science Foundation. The study was supported by the Cystic Fibrosis Australia Research Trust.

Competing interests: none.

A Moeller and F Horak have equal first author responsibility for this study.

\section{REFERENCES}

1 Silkoff PE, Robbins RA, Gaston B, et al. Endogenous nitric oxide in allergic airway disease. J Allergy Clin Immunol 2000;105:438-48.

2 Elphick HE, Demoncheaux EA, Ritson S, et al. Exhaled nitric oxide is reduced in infants with cystic fibrosis. Thorax 2001;56:151-2.

3 Grasemann H, Michler E, Wallot M, et al. Decreased concentration of exhaled nitric oxide (NO) in patients with cystic fibrosis. Pediatr Pulmonol 1997;24:173-7.

4 Lundberg JO, Nordvall SL, Weitzberg E, et al. Exhaled nitric oxide in paediatric asthma and cystic fibrosis. Arch Dis Child 1996;75:323-6. 
5 Balfour-Lynn IM, Laverty A, Dinwiddie R. Reduced upper airway nitric oxide in cystic fibrosis. Arch Dis Child 1996;75:319-22.

6 Dotsch J, Demirakca S, Terbrack HG, et al. Airway nitric oxide in asthmatic children and patients with cystic fibrosis. Eur Respir J 1996:9:2537-40

7 Lane C, Knight D, Burgess S, et al. Epithelial inducible nitric oxide synthase activity is the major determinant of nitric oxide concentration in exhaled breath. Thorax 2004;59:757-60

8 Kelley TJDrumm ML. Inducible nitric oxide synthase expression is reduced in cystic fibrosis murine and human airway epithelial cells. J Clin Invest 1998; 102:1200-7.

9 Meng QH, Springall DR, Bishop $A E$, et al. Lack of inducible nitric oxide synthase in bronchial epithelium: a possible mechanism of susceptibility to infection in cystic fibrosis. J Pathol 1998;184:323-31.

10 Moncada S, Palmer RMHiggs EA. Nitric oxide: physiology, pathophysiology, and pharmacology. Pharmacol Rev 1991;43:109-42.

11 Ottaviani E, Paeman LR, Cadet P, et al. Evidence for nitric oxide production and utilization as a bacteriocidal agent by invertebrate immunocytes. Eur J Pharmacol 1993;248:319-24.

12 Schmidt HH, Walter U. NO at work. Cell 1994;78:919-25.

13 Wooldridge JL, Deutsch GH, Sontag MK, et al. NO pathway in CF and nonCF children. Pediatr Pulmonol 2004;37:338-50.

14 Meng QH, Polak JM, Edgar AJ, et al. Neutrophils enhance expression of inducible nitric oxide synthase in human normal but not cystic fibrosis bronchial epithelial cells. J Pathol 2000;190:126-32.

15 Kanga J, Kuhn R, Craigmyle L, et al. Cystic fibrosis clinical score: a new scoring system to evaluate acute pulmonary exacerbation. Clin Ther 1999;21:1343-56.

16 Ferris B. Epidemiology Standardization Project (American Thoracic Society). Am Rev Respir Dis 1978;118:1-120.

17 Lane C, Burgess S, Kicic A, et al. The use of non-bronchoscopic brushings to study the paediatric airway. Respir Res 2005;6:53.

18 Pfaffl MW. A new mathematical model for relative quantification in real-time RT-PCR. Nucl Acids Res 2001;29:e45.

19 Riedler J, Grigg J, Stone C, et al. Bronchoalveolar lavage cellularity in healthy children. Am J Respir Crit Care Med 1995;152:163-8.

20 Marguet C, Jouen-Boedes F, Dean TP, et al. Bronchoalveolar cell profiles in children with asthma, infantile wheeze, chronic cough, or cystic fibrosis. Am J Respir Crit Care Med 1999;159:1533-40.

21 Darling KE, Evans TJ. Effects of nitric oxide on Pseudomonas aeruginosa infection of epithelial cells from a human respiratory cell line derived from a patient with cystic fibrosis. Infect Immun 2003;71:2341-9.

22 Morrissey BM, Schilling K, Weil JV, et al. Nitric oxide and protein nitration in the cystic fibrosis airway. Arch Biochem Biophys 2002;406:33-9

23 Steagall WK, Elmer HL, Brady KG, et al. Cystic fibrosis transmembrane conductance regulator-dependent regulation of epithelial inducible nitric oxide synthase expression. Am J Respir Cell Mol Biol 2000;22:45-50.

24 Khan TZ, Wagener JS, Bost $T$, et al. Early pulmonary inflammation in infants with cystic fibrosis. Am J Respir Crit Care Med 1995;151:1075-82.

25 Formanek W, Inci D, Lavener RP, et al. Elevated nitrite in breath condensates of children with respiratory disease. Eur Respir J 2002;19:487-91.
26 Linnane SJ, Keatings VM, Costello CM, et al. Total sputum nitrate plus nitrite is raised during acute pulmonary infection in cystic fibrosis. Am J Respir Crit Care Med 1998; 158:207-12.

27 Grasemann H, loannidis I, Tomkiewicz RP, et al. Nitric oxide metabolites in cystic fibrosis lung disease. Arch Dis Child 1998;78:49-53.

28 Zheng S, Xu W, Bose S, et al. Impaired nitric oxide synthase-2 signaling pathway in cystic fibrosis airway epithelium. Am J Physiol Lung Cell Mol Physiol 2004;287:L374-81.

29 Khan TZ, Wagener JS, Bost T, et al. Early pulmonary inflammation in infants with cystic fibrosis. Am J Respir Crit Care Med 1995;151:1075-82.

30 Rosenfeld M, Gibson RL, McNamara S, et al. Early pulmonary infection, inflammation, and clinical outcomes in infants with cystic fibrosis. Pediatr Pulmonol 2001;32:356-66.

31 Burns JL, Gibson RL, McNamara S, et al. Longitudinal assessment of Pseudomonas aeruginosa in young children with cystic fibrosis. J Infect Dis $2001 ; 183: 444-52$

32 Kosorok MR, Zeng L, West SE, et al. Acceleration of lung disease in children with cystic fibrosis after Pseudomonas aeruginosa acquisition. Pediatr Pulmonol 2001;32:277-87.

33 Nixon GM, Armstrong DS, Carzino R, et al. Clinical outcome after early Pseudomonas aeruginosa infection in cystic fibrosis. J Pediatr 2001; 138:699-704.

34 Grasemann H, Knaver N, Buscher R, et al. Airway nitric oxide levels in cystic fibrosis patients are related to a polymorphism in the neuronal nitric oxide synthase gene. Am J Respir Crit Care Med 2000;162:2172-6.

35 Francoeur C, Denis $M$. Nitric oxide and interleukin-8 as inflammatory components of cystic fibrosis. Inflammation 1995;19:587-98.

36 Gosselin D, DeSanctis J, Boule M, et al. Role of tumor necrosis factor alpha in innate resistance to mouse pulmonary infection with Pseudomonas aeruginosa. Infect Immun 1995;63:3272-8.

37 Yu H, Nasr SZ, Deretic V. Innate lung defenses and compromised Pseudomonas aeruginosa clearance in the malnourished mouse model of respiratory infections in cystic fibrosis. Infect Immun 2000;68:2142-7.

38 Lee J, Ryu H, Ferrante R, et al. Translational control of inducible nitric oxide synthase expression by arginine can explain the arginine paradox. Proc Natl Acad Sci USA 2003; 100:4843-8.

39 Grasemann H, Schwiertz R, Matthiesen S, et al. Increased arginase activity in cystic fibrosis airways. Am J Respir Crit Care Med 2005;172:1523-8.

40 Dormer L, Harris CM, Clark Z, et al. Sildenafil (Viagra) corrects DeltaF508CFTR location in nasal epithelial cells from patients with cystic fibrosis. Thorax 2005;60:55-9

41 Elmer H, Brady K, Drumm M, et al. Nitric oxide-mediated regulation of transepithelial sodium and chloride transport in murine nasal epithelium. Am J Physiol 1999;276:466-73

42 Kamosinska B, Radomski M, Duszyk M, et al. Nitric oxide activates chloride currents in human lung epithelial cells. Am J Physiol 1997;272:1098-104.

43 Cobb B, Fan L, Kovacs T, et al. Adenosine receptors and phosphodiesterase inhibitors stimulate $\mathrm{Cl}^{-}$secretion in calu-3 cells. Am J Respir Cell Mol Biol 2003;29:410-8. 